\title{
Foucault, Governamentalidade Neoliberal e Subjetivação
}

\author{
Joao Leite Ferreira Neto* (D) \\ Pontificia Universidade Católica de Minas Gerais, Belo Horizonte, MG, Brasil
}

\begin{abstract}
RESUMO - O artigo visa compreender as posições teórico-políticas de Foucault construídas a partir de 1978, com o estabelecimento das noções de governamentalidade e subjetividade como eixos de suas pesquisas. Discute-se aspectos histórico-institucionais relacionados ao seu deslocamento teórico na direção do tema do governo e seu afastamento da esquerda, fontes biográficas e textos do autor publicados entre 1978 e 1980 . Em segundo lugar, analisa-se uma entrevista sobre a crise do sistema de seguridade social, buscando entender seu posicionamento em relação ao tema. Conclui-se que Foucault utilizou tanto de contribuições marxistas, quanto neoliberais, evitando reduzir a política ao enfrentamento entre dois projetos, mas considerando-a um campo complexo de estratégias plurais. A subjetividade coloca-se para Foucault na interface entre a política e a ética.
\end{abstract}

PALAVRAS chave: Michel Foucault, poder, subjetividade, psicologia política

\section{Foucault, Neoliberal Governmentality, and Subjectivation}

\begin{abstract}
This article aims to understand Foucault's theoretical and political positions, which were built from 1978 on, with the establishment of governmentality and subjectivity notions as an axis of his researches. It discusses historical aspects that are related to his theoretical shift into government's subject, biographical sources, and author texts, which were published between 1978 and 1980. Second, it analyzes an interview about the crisis of the social security system, seeking to understand his position about the issue. It concludes that Foucault used both Marxist and neoliberal contributions, avoiding to reduce politics into a confrontation between the two projects, but considering it as a complex field of plural strategies. The subjectivity places at the interface between politics and ethics.
\end{abstract}

KEYWORDS: Michel Foucault, power, subjectivity, political psychology

Até sua morte em 1984, Foucault era conhecido principalmente através de seus nove livros completos publicados, a maioria deles publicado no chamado período arqueológico, até 1969. Depois disso, sincronicamente à sua entrada no Collège de France em 1970, seu ritmo de publicação de livros desacelerou, havendo inclusive uma grande lacuna entre 1976 e 1984. Contudo, havia ainda textos isolados, entrevistas, artigos ou trechos de curso, que foram publicados durante sua vida e um extenso material inédito, envolvendo entrevistas e artigos publicados em outros países que visitou, além dos cursos no Collège de France.

Em sua carta testamento Foucault expressou a recomendação: "sem publicações póstumas" (Defert, 1999, p. 64). Não obstante, ocorreu uma primeira publicação póstuma em 1994, organizada por Daniel Defert e François Ewald, Dits et écrits, contendo um vasto conjunto de entrevistas e artigos, com a justificativa de que seriam somente textos que apareceram durante sua vida, publicados na França ou no exterior. Mesmo assim, em 1997, começaram a ser publicados todos os cursos dados por Foucault no Collège de France. Segundo Elden (2016, p. 4), o desejo de Foucault de não haver escritos póstumos foi, inicialmente, "seguido fielmente, depois interpretado generosamente e atualmente é quase completamente ignorado".

De qualquer modo, as escolhas tomadas sobre a realização dessas publicações póstumas exigem novas

\footnotetext{
*E-mail: jleite.bhe@terra.com.br

- Submetido: 27/12/2016; Aceito: 10/01/2018.
} 
leituras e interpretações de sua obra, com base em materiais que portavam aspectos inéditos em relação aos seus livros publicados. Talvez o tema que emergiu de modo mais intenso foi o da governamentalidade, elaborado nos cursos Segurança, território e população de 1978 e Nascimento da biopolítica de 1979, e se perpetuou nos anos seguintes, demonstrando ser um conceito crucial na arquitetura de sua obra (Ferreira Neto, 2015). Os dois cursos se dedicam ao estudo da razão de Estado desde o século XVII até o século $\mathrm{XX}$, sendo que o segundo dá especial atenção à governamentalidade neoliberal. $\mathrm{O}$ fato de Foucault ter mostrado interesse pelo projeto neoliberal, sem realizar sua crítica, produziu diversas interpretações, entre as quais, que ele teria aderido ao neoliberalismo. Publicações recentes levantaram esse debate, (Lagasnerie, 2013; Zamora 2014), desencadeando variadas reações (Audier, 2015; Bang, 2015; Dean, 2015).

Seu curso de 1979 sobre o neoliberalismo, revelou-se premonitório. Um mês após seu encerramento, Margareth Thatcher foi eleita primeira ministra do Reino Unido, e no final do ano Ronald Reagan eleito presidente dos Estados Unidos. Ambos são tidos como arautos da implementação das políticas neoliberais, que até então havia tido algumas iniciativas pontuais na Alemanha de Helmut Schmidt e na França de Giscard d'Estaing, ambas abordadas por Foucault, mas sem adquirir a hegemonia no debate político-econômico que conquistou nos anos 1980 e 1990.

É importante notar que o escopo da análise foucaultiana do neoliberalismo no curso Nascimento da Biopolítica (Foucault, 2008b) não abarcou experiências políticas de implementação no ideário neoliberal. Seu corpus envolveu, fundamentalmente, textos programáticos e artigos de economistas, visando entender a racionalidade neoliberal, e não sua implantação como programa de governo. Como assinala Dean (2016), Foucault, nesse curso, se atém a análise dos objetivos e da racionalidade neoliberal, em vez de abordar suas tecnologias e modos de implantação, como fez em seu curso anterior ao analisar as tecnologias de segurança (Foucault, 2008a).

A noção de governamentalidade, ou de governo, passou a ocupar, desde 1978, um lugar central na pesquisa de Foucault, sendo condutora de certa virada no seu posicionamento teórico e político. Este passou a considerar o poder como sendo menos da ordem do "enfrentamento entre dois adversários", como propugnava na primeira metade dos anos 1970, mas da ordem do governo. Esse deve ser entendido em uma acepção ampliada, designando tanto as estruturas políticas e gestão do Estado, quanto o modo de "dirigir a conduta de indivíduos e grupos" (Foucault, 1982/2014a, p. 133). Envolve, além disso, o que ele passa a chamar a partir de 1980 de "governo de si". Trata-se, portanto, de um conceito que abarca tanto o individual, quanto o coletivo, e inclui as macroestruturas institucionais. É um conceito transversal, que perpassa variadas dimensões da vida institucional, coletiva e individual. Ao elaborar esta noção em 1978, Foucault afirma que na medida em que o pastorado, embrião da governamentalidade moderna, criou o primeiro esboço do governo dos homens, concomitantemente aguçou outro apetite: "como ser sujeito sem ser sujeitado?". (Foucault, 2008a, p. 310). Ou seja, ao introduzir o eixo da governamentalidade em suas pesquisas a partir de 1978, Foucault foi conduzido a retomar o tema da subjetividade não apenas na perspectiva das "práticas coercitivas", como vinha fazendo antes, mas no âmbito das práticas de si e das práticas de liberdade (Foucault, 1984/2004e, p. 264).

O governo se revelou um conceito bastante operacional, permitindo tanto o estudo da governamentalidade do Estado, quanto a ética da subjetivação, ambos, como processos indissociáveis. Pela primeira vez, a subjetividade passou a ser pensada como uma faceta distinta da alma docilizada do poder, pelas práticas coercitivas, até então o foco de suas pesquisas. A partir de então, Foucault pôde explorar as práticas de si, como práticas da liberdade, tema derradeiro de seus estudos.

Em seu curso de 1981, Foucault sintetizou seu projeto como o cruzamento de "uma história da subjetividade e uma análise das formas de governamentalidade" (Foucault $1981 / 2014$ b, p. 350). Doravante ele se interessaria pelo sujeito que age, que se autogoverna, construindo sua autonomia diante do governo. Subjetivação se torna o nome derradeiro do que outrora ele chamou de resistência e de contraconduta.

O objetivo deste artigo é entender as posições teóricopolíticas de Foucault construídas a partir de 1978, com estabelecimento da noção de governamentalidade como eixo central de suas pesquisas, e da subjetividade como dimensão política e ética. Inicialmente, discute-se aspectos históricos que concorreram para seu deslocamento teórico na direção do tema do governo e seu afastamento da esquerda maoísta, da qual até então, era próximo, conectando com seu contexto histórico-institucional com base na "Situação dos Cursos" escrita por Senellart (2008), mostrando dados biográficos e textos escritos por Foucault entre 1978 e 1980. Em segundo lugar, analisa-se uma entrevista dada em 1983 sobre a crise do sistema de seguridade social francês, buscando entender seu posicionamento em relação ao tema (Foucault, 1983/2004a). A escolha dessa entrevista em detrimento do curso sobre o neoliberalismo, se deu por duas razões. A primeira delas é a prevalência na literatura. Enquanto Nascimento da Biopolítica é o curso mais comentado de Foucault, esta entrevista tem sido "quase completamente ignorada pela literatura sobre governamentalidade e raramente citada por foucaultianos" (Dean, 2015, p. 102). A segunda é seu caráter de abordagem de aspectos práticos sobre um tema central no debate entre keynesianos e neoliberais: a crise no sistema de seguridade social.

Meu argumento central acompanha a interpretação de Flew (2012, p. 49), entre outros, de que a posição política de Foucault ocupa "um espaço político mais ambíguo", do que sugerem as interpretações frequentes, que ainda o 
situam como um pensador da esquerda. Como veremos, se por um lado Foucault não se tornou um neoliberal, por outro, sua posição política não deveria mais ser apreendida dentro do binarismo convencional de esquerda-direita. Ele será melhor entendido como havendo desenvolvido um ethos crítico que o conduziu a um incessante movimento intelectual caracterizado como "uma modalidade de crítica não-normativa” (Trianfillou, 2012, p. 12).

Foucault é um autor muito utilizado por psicólogos, seja em estudos acadêmicos, seja no campo profissional, especialmente nas políticas públicas de saúde (Ferreira Neto, Moreira, Araújo, \& Drawin, 2017). Em uma pesquisa feita em fevereiro de 2016, na biblioteca SciELO, com o descritor Foucault, encontraram-se 169 entradas. Classificando-se os periódicos por área de conhecimento, as três primeiras colocações ficaram com a Psicologia, com 59 artigos, a Educação com 34 e a Sociologia, com 20. Ou seja, nossa área aproxima-se do dobro da Educação e do triplo da Sociologia. Entendo que o recurso ao filósofo por parte de psicólogos no Brasil tende a aumentar, na medida em que sua discussão sobre subjetividade, desenvolvida principalmente nos Ditos e Escritos e nos cursos, foi publicada mais recentemente. Portanto, a discussão aprofundada de seus conceitos, articulada à sua gênese histórico-institucional, pode ser uma contribuição relevante para a área.

Dentre os variados fatores que concorrem para o interesse dos psicólogos na obra de Foucault, está o fato de que nossa profissão tem tido, nos últimos anos, o campo das políticas públicas como seu principal contratante (Bastos \& Gondim, 2010). Assim, a análise dos conceitos de governamentalidade, subjetivação e a discussão sobre a seguridade social, pilares da construção deste artigo, podem ser ferramentas conceituais úteis na relação dos psicólogos com o autor.

\section{DA GUERRA AO GOVERNO:ASPECTOS HISTÓRICOS}

A hipótese inicial é de que 1977, seu ano sabático no Collège de France, constituiu-se um ponto de virada na trajetória política e de pesquisa de Foucault. Senellart (2008) assevera que o filósofo deslocou o centro de gravidade dos cursos da questão do biopoder, para a do governo. A interpretação majoritária na literatura, mesmo que não exclusiva, é de que Foucault abandonou a noção de biopolítica em favor da noção de governamentalidade. Castro-Gómez (2011, p. 63), considera a biopolítica um conceito provisório, que "cumpre a função de ponte entre o modelo bélico e o modelo governamental”. Mesmo sendo anunciado no título de 1979, Nascimento da biopolítica, o conceito não é explorado no curso e não é mais retomado pelo filósofo em textos posteriores, à exceção de uma resposta dada em entrevista (Ferreira Neto, 2015).

Senellart (2008) realça três episódios que comportam elementos esclarecedores das condições históricas, que propiciaram a construção de Foucault do tema da governamentalidade e da mudança de sua posição política: sua aproximação da chamada "Segunda Esquerda" francesa; seu envolvimento com o caso Klaus Croissant; e seu trabalho de "reportagem de ideias", realizado durante a revolução iraniana.

Em relação ao primeiro episódio, em junho de 1977, durante o congresso do Partido Socialista, Michel Rocard distinguiu duas culturas políticas de esquerda. A primeira jacobina e estatizante e a segunda antiestatista e descentralizadora, que ficou conhecida como Segunda Esquerda (Defert, 1999, p. 47). Esta, se distanciava do marxismo clássico, incorporando temas como a vida cotidiana, a situação das mulheres, a autogestão, entre outros, elaborando uma agenda próxima à de Maio de $68 \mathrm{e}$ do próprio Foucault. Meses depois, em setembro, Foucault participou ativamente de um fórum sobre esquerda e experimentação social, defendendo que a inovação não passava mais pelos partidos, mas pela inquietação ética individual (Foucault, 1977/2012a, p. 92). Behrent (2016, p. 38 ) entende que o interesse de Foucault pelo neoliberalismo decorre de sua aproximação da Segunda Esquerda.

Vale acentuar o porquê pode-se falar em uma virada política de Foucault nesse período. Na juventude, Foucault foi membro do Partido Comunista, mas se desfiliou em 1953. Durante vários anos utilizava conceitos marxistas em alguns textos e entrevistas, mas os foi abandonando progressivamente. Quando Foucault voltou à França após o Maio de 68, encontrou parte da esquerda se afastando da experiência soviética em favor do maoísmo chinês. Ao assumir cargo de gestão na recém-criada Universidade Experimental de Vincennes, nomeou vários militantes maoístas como Alain Badiou, Jacques Rancièrre, André Glucksman e Jacques-Alain Miller. Afinado com o espírito político da instituição: para lecionar na filosofia era necessário "ter participado de maio de 68" e pertencer a algum grupelho (Eribon, 1990, p. 189). Com um desses grupos, a Gauche Prolétarienne, Foucault teve bastante proximidade.

A Gauche Prolétarienne buscava envolver a participação das massas do setor fabril, realizar pesquisas sobre o cotidiano das pessoas e estabelecer uma forma de justiça popular. Segundo Karlsen e Villadsen (2014), o trabalho genealógico de Foucault no Grupo de Informações (GIP) sobre as prisões, tem clara inspiração nas técnicas de investigação maoístas, bem como seu modelo bélico do poder. O GIP compartilhava a ideia da esquerda francesa de que a política convencional era uma forma que ocultava os "reais mecanismos de opressão" (Karlsen \& Villadsen, 2014, p. 104). 
A proximidade de Foucault com a esquerda maoísta não implicava uma adesão integral às suas teses e métodos, como podemos ver em seu debate sobre a Justiça Popular, com militantes maoístas (Foucault, 1972/2010a). Sua ligação com a genealogia nietzschiana lhe permitia sustentar um importante distanciamento crítico do maoísmo, ao mesmo tempo em que bebia dessa fonte. Mesmo assim ele acabou se desembaraçando dessa influência, abandonando a crença na ideia de revolução e, principalmente, nas estratégias violentas de luta política, como o episódio seguinte demonstra.

O segundo elemento envolvendo a virada política de Foucault foi seu decisivo apoio à não extradição de Klaus Croissant, advogado defensor do grupo de Baader. Foucault não poupa esforços nessa empreitada, escrevendo vários textos e manifestos, que serão explorados na sequência, e participando de manifestações de rua. Mesmo assim, Croissant acabou extraditado no final de 1977.

Como lembra Eribon (1990, p. 239), a posição de Foucault já não era mais de esquerda. Isso o levou a romper com um de seus mais caros amigos, Gilles Deleuze. No caso em questão, Foucault queria defender o advogado, mas não seus clientes, que considera terroristas, se recusando, por isso, a assinar um segundo manifesto mais amplo, assinado por Guattari e Deleuze, que acusava inclusive a Alemanha de haver se tornado um estado policial. Desde então ele se afastou do amigo. Anos mais tarde, confidenciaria a Mauriac sobre o motivo de seu afastamento de Deleuze, desde Klaus Croissant: "Eu não aceitava o terrorismo e o sangue, não aprovava Baader e seu bando" (Eribon, 1990, p. 242). Posteriormente, em seus últimos anos, Foucault manifestou seu desejo de rever Deleuze, o que acabou não ocorrendo, mas foi Deleuze quem conduziu as exéquias no sepultamento, a convite de Defert, lendo, sob forte emoção, um trecho de sua obra.

Mas qual foi o debate teórico construído durante a luta pela não extradição de Croissant? Podemos sintetizar suas ideias em dois textos da época, nos quais Foucault aborda esse caso. No primeiro texto, ele defende Croissant em nome do "direito dos governados", considerado "mais historicamente determinado que os direitos humanos", mas cuja teoria ainda carecia de formulação (Foucault, 1977/2012b, p. 96). Seus cursos a partir de 1978, esboçam o formato dessa teorização, indo do conceito de governamentalidade e contracondutas ao de parresia. No mesmo ano ele o descreve como sendo uma forma de crítica, que no curso de 1979 associaria à emergência das democracias liberais: "a arte de não ser governado de tal forma" (Foucault, 1978, p. 4).

Em novembro de 1977, após a extradição de Croissant, Foucault concedeu uma entrevista na qual reconhecia a omissão da esquerda no caso, apontando como é difícil fazer "a crítica ou a autocrítica da esquerda" (1977/2010b, p. 172). Anuncia a emergência das sociedades de segurança, nas quais o Estado tem um pacto de segurança com a população, para garanti-la contra toda a incerteza, mediante a seguridade social. Em função disso vocaciona-se uma tendência de totalitarismo de Estado, que precisa fazer "um controle preciso de tudo (p. 173), tema que ele retomará na entrevista de 1983. Entretanto, Foucault diferencia essa experiência Ocidental em curso, do totalitarismo em sentido estrito, no qual os partidos políticos, os aparelhos de Estado, os sistemas institucionais, a ideologia, aderem a uma espécie de unidade que é controlada de alto a baixo, sem fissuras" (p. 173). Segundo ele, não podemos intitular as democracias liberais, de Estado fascistas, apesar de tenderem a um controle extremado sobre suas populações, em nome da segurança. Foucault aposta na consciência política das pessoas que não compram a ideia de estarem vivendo em um Estado fascista, forte elemento da retórica da esquerda. Na verdade, as pessoas sabem que a vigilância constante dos mecanismos de segurança social "não é o fascismo, mas alguma coisa nova" (Foucault, 1977/2010b, p. 175). O interesse de Foucault é a análise da emergência das tecnologias de segurança. Não as condena a priori, mas localiza seu contraponto na arte de não ser governado de determinada forma, o histórico direito dos governados.

O terceiro episódio de que nos fala Senellart (2008) foi o envolvimento de Foucault em uma "reportagem de ideias" sobre a revolução iraniana, para um periódico italiano. Não será possível nesse espaço fazer a análise deste que foi um dos episódios mais polêmicos da biografia de Foucault. Senellart (2008) realizou uma boa síntese desse debate. Apenas saliento que Foucault realizou duas visitas ao país no início dos protestos, a segunda delas em novembro de 1978, durante as maiores manifestações contra o Xá, mas anteriores à sua queda e à instalação do "governo sangrento do clero fundamentalista" em fevereiro de 1979 (Foucault, 1979/2004a, p. 79).

O fato é que Foucault se encantou com o que testemunhou e, acompanhando os iranianos, não a chama de revolução, mas de manifestação, insurreição, dando-lhe um estatuto similar ao que chamou no curso 1978 de contraconduta. Com a ocupação do poder do aiatolá Khomeini, marcada pela extrema violência contra os opositores do regime, Foucault foi duramente criticado pela esquerda e pela direita. Ele não polemizou, mas escreveu um artigo no Le Monde em maio de 1979, intitulado "É inútil revoltar-se?" (Foucault, 1979/2004a).

No artigo, Foucault afirma a importância da insurreição, individual e coletiva, que reivindica a não obediência ao poder. Distingue cuidadosamente insurreição de revolução, parâmetro, à época, da mentalidade de esquerda. Segundo ele, o que se passou no Irã é algo novo em relação aos padrões ocidentais. Ele percebia uma espiritualidade nos homens e mulheres que arriscaram suas vidas na revolta contra o Xá, diferente da violência sangrenta do clero fundamentalista que a sucedeu. É o momento no qual "uma singularidade se insurge", que ele valoriza. Por isso não concorda com o argumento de que é inútil se "insurgir, sempre será a mesma coisa" (Foucault, 1979/2004a, p. 80). A 
insurreição define o momento em que a subjetividade comum se introduz na história e lhe dá seu alento, uma subjetividade não exclusivamente psicológica, mas de viés político e ético. Ao final, Foucault insiste que o poder não é necessariamente um mal, porém é interminável. Por essa razão, é necessário impor-lhe regras, limites, restrições, sempre.

Vale introduzir aqui três dimensões que caracterizam a noção de subjetividade, entendida como prática de si, em Foucault. Em primeiro lugar há uma diferenciação entre a subjetividade tomada como assujeitamento e a subjetividade como atitude crítica ou prática de si. Lorenzini (2016, p. 63) sugere que a preocupação de Foucault não era com um sujeito autônomo ou não, mas se este "está disposto a se tornar sujeito da crítica, se opondo aos mecanismos de poder governamental". Há, portanto, uma relação necessária entre o governo de si e dos outros. Em segundo lugar, a prática de si não consiste em um trabalho intraindividual, mas coletivo e institucional, como vemos na ligação feita por Foucault entre a insurreição iraniana e a subjetividade que se introduz na história. Finalmente, tanto na subjetivação assujeitada quanto na autônoma, há um tipo próprio de relação com normas extraídas da cultura. Ou seja, não se trata de pensar práticas de liberdade na ausência ou recusa de normas, mas no uso autônomo das mesmas. Esses três aspectos estão sintetizados em um trecho de entrevista dada por Foucault:

Em primeiro lugar, penso efetivamente que não há um sujeito soberano, fundador, uma forma universal de sujeito que poderíamos encontrar em todos os lugares. Eu sou muito cético e hostil em relação a essa concepção de sujeito. Penso, pelo contrário, que o sujeito se constitui através das práticas de sujeição (assujeitamento) ou, de uma maneira mais autônoma, através das práticas de liberação, de liberdade, como na Antiguidade - a partir, obviamente, de um certo número de regras, de estilos, de convenções que podemos encontrar no meio cultural". (Foucault, 1984/2004e, p. 291)

Além dos episódios arrolados por Senellart (2008), podese acrescentar uma prática, distinta das anteriores. Foucault mantinha um seminário privado paralelo a seus cursos no Collège de France. Entre 1976 e 1980, aprofundava neles sua discussão sobre política (Behrent, 2010), tornando-se um laboratório de produção de uma nova filosofia política que funcionasse como uma alternativa ao marxismo. Participavam dessa empreitada ativistas da geração de 1968, entre os quais estavam François Ewald, Alessandro Fontana, Giovana Procracci, Pierre Rosavalon, um economista ligado à Segunda Esquerda. Parte desses estudos foi explorada nos seus cursos oficiais de 1978 e 1979. Posteriormente, vários desses estudantes produziram trabalhos sobre políticas públicas e Welfare State, e alguns atuaram como consultores junto ao governo francês.
A descrição que o estudo de Behrent (2010) realiza desses seminários naquele período, a partir dos depoimentos de alguns participantes, era de ocorrer uma espécie de terapia política grupal de engajamento maoísta que tiveram anteriormente, com base não na psicanálise, mas nos estudos históricos. O conceito de governamentalidade ajudou Foucault e os membros do seminário a compreenderem a centralidade do Welfare State nos arranjos de poder do Estado moderno - uma descoberta que exigiu, segundo Ewald afirmou, nada menos do que uma "conversão espiritual". O grupo de pesquisa elaborou uma nova apreciação da complexidade das técnicas governamentais modernas como não meramente repressivas e disciplinares, mas também como "abertas e manejáveis" (Behrent, 2010, p. 587), rompendo com o maniqueísmo moralista de denúncia do poder como necessariamente opressivo. Eles perceberam que essa "nova política filosófica" de Foucault oferecia não somente um caminho para abandonar o marxismo, mas também uma alternativa às políticas de esquerda de denúncia moral. Eribon (1990) salienta o gosto de Foucault por esses seminários privados, que associavam seu trabalho ao de seus orientandos, como espaço altamente valorizado de trabalho intelectual (p. 238-239).

Em 1978, dialogando com um interlocutor japonês, Foucault afirmou que o marxismo é um "objeto do qual se precisa desembaraçar-se" (Foucault,1978/2010c, p. 190). E para realizar a ultrapassagem do marxismo é preciso "não cair na armadilha das soluções tradicionais". Importa criar um novo imaginário político, e não simplesmente assumir um ideário já existente. A construção desse imaginário político envolve, um trabalho sobre si, um processo de subjetivação. Essa é uma dimensão do trabalho intelectual que sempre foi acentuada por Foucault. Em entrevista dada a Ewald afirmou: "Um trabalho, quando não é, ao mesmo tempo, uma tentativa de modificar o que se pensa e mesmo o que se é, não é muito interessante" (Foucault, 1984/2004d, p. 240). Assim, a subjetivação se estabelece tanto na insurreição política diante de uma situação específica, quanto na insurreição intelectual em relação às tradições teóricas, às alianças ideológicas, e ao que se pensava antes.

Em resumo, Foucault, desde 1978, desenvolveu uma reflexão política sobre "a arte de não ser de tal forma governado", sobre o direito dos governados, sobre a insurreição. Isso lhe demandou retomar a noção de subjetividade, não mais como docilidade, submetimento, mas como prática de liberdade. A crítica será doravante "a arte da inservidão voluntária, aquela da indocilidade irrefletida" (Foucault, 1978, p. 3). Esse processo da crítica envolve o trabalho de pensar diferentemente, desprenderse de crenças anteriores e de si mesmo, e contaminou a atmosfera dos seminários privados nas discussões sobre governamentalidade e sobre o Welfare State. 


\section{NEOLIBERALISMO E SEGURIDADE SOCIAL}

Foucault sempre recusou ser classificado por alguma posição política de princípio, sendo capaz de elencar várias que lhe atribuíam alguma identidade, seja anarquista, marxista, antimarxista, niilista ou mesmo neoliberal (Foucault, 1984/2004c). Porém, no resumo do curso de 1979, se apoiou em uma avaliação de Paul Veyne, para definir sua identidade de trabalho como "um método nominalista em história" (Foucault, 1979/2008b, p. 432). No mesmo curso direcionou seu trabalho propondo: "suponhamos que os universais não existam" (p. 5). Esse caminho havia sido tomado em seu trabalho anterior sobre a loucura e em sua discussão sobre o Estado. Foucault não os toma como universais, mas esquadrinha o conjunto de práticas que os fez emergir. Sob essa perspectiva, devemos entender sua análise do neoliberalismo.

Esse nominalismo metodológico conduz Foucault a um tipo de crítica política que pode ser classificada como predominantemente não normativa, ou descritiva. Acentuo o "predominantemente", por entender que, mesmo parcimoniosamente, Foucault defende certos valores, nos quais ancora sua crítica, como veremos na entrevista a ser analisada adiante.

Em relação ao neoliberalismo, há uma preocupação de parte da literatura foucaultiana em denunciar o uso abusivo desse conceito. Cotoi (2011) sugere que o neoliberalismo se tornou um modismo generalizante, ao designar tanto na academia, quanto na imprensa, as práticas políticas as quais se quer criticar. Isso é particularmente forte na literatura marxista, como no trabalho de Dardot e Laval (2016), que mesmo parcialmente inspirados em Foucault, apresentam o neoliberalismo como "a nova razão do mundo".

Flew (2012, p. 45) analisa a proliferação do uso do termo como tendo um conteúdo de denúncia moral, ou uma forma de se "referir às más ideias defendidas por outros". De fato, não é raro em um debate alguém argumentar: "isso é neoliberal", como estratégia de desqualificação, em vez de realizar o aprofundamento dos argumentos específicos de discordância. Concordo com Kipnis (2008), em seus estudos antropológicos sobre a cultura de avaliação na China, quando considera que a classificação de uma governamentalidade neoliberal "mais mascara que ilumina" a análise (p. 280). Afirma ainda que o exame detalhado da implementação das tecnologias de avaliação em diferentes contextos é mais importante, que uma "crítica ideológica do neoliberalismo per se" (p. 285).

Esse uso generalizante da noção de neoliberalismo está distante da discussão empreendida por Foucault, que não o tomava como um universal abstrato, mas analisa-o em suas dimensões locais: o neoliberalismo alemão e o americano, este último, da Escola de Chicago. Ambos possuem diferenças histórico-institucionais e algumas características em comum. $\mathrm{O}$ combate às proposições de Keynes, que subsidiaram a construção dos welfare states, a crítica ao intervencionismo estatal e a inspiração na escola econômica austríaca de Von Mises e Hayek (Foucault, 2008b, pp. 107108). Esses neoliberalismos visavam generalizar a forma "empresa" para o conjunto da sociedade, utilizando o aparato estatal para garantir a competição, ao mesmo tempo que restringiam a discricionariedade estatal.

Dois elementos levam alguns autores a supor certo alinhamento de Foucault ao neoliberalismo. Um deles foi a descrição feita por Foucault da emergência de uma nova arte de governar no século XVIII, o liberalismo, como uma crítica ao excesso de governo (não se trata ainda do neoliberalismo). Trata-se, portanto, da "arte de governar o menos possível” (Foucault, 1979/2008b, p. 40). Essa nova racionalidade de governo busca o autolimite do governo não mais na via do direito, mas com base na economia política, entendida em um sentido lato como um método de governo que visa assegurar a prosperidade de uma nação. Entre outras facetas, ela interroga as práticas de governo não em "termos de direito, para saber se são legítimas ou não", mas por seus efeitos (p. 21). Substitui, assim, a legitimidade pelo sucesso, ou, em uma linguagem contemporânea, pelos resultados. Há que se destacar o interesse de Foucault na dimensão econômica do neoliberalismo. Seu curso não explorou o liberalismo político de Benjamin Constant ou Tocqueville, mas o trabalho de economistas neoliberais como Adam Smith e Gary Becker (Behrent, 2016).

Chama a atenção a similaridade entre a razão liberal e o que Foucault chama de crítica, bem como sua preocupação em estabelecer restrições ao poder, em nome do direito dos governados. Com base na argumentação anterior de que Foucault visava construir uma nova imaginação política, essa aparente proximidade entre a crítica genealógica e a arte liberal de governo, não deve ser tomada como signo de identidade. Se Foucault retorna ao liberalismo, e explora o neoliberalismo, era parte de sua trajetória de construção de uma nova filosofia política, não marxista, mas que também não seria um decalque do liberalismo, ainda que fosse imanente às democracias liberais nas quais viveu.

$\mathrm{O}$ segundo fator deriva do fato de que, ao descrever o neoliberalismo americano, Foucault ressalta sua renúncia em forjar uma sociedade exaustivamente disciplinar, mas uma sociedade "na qual haveria otimização dos sistemas de diferença, [...], em que haveria uma tolerância concedida aos indivíduos e às práticas minoritárias" (Foucault, 2008b, p. 354). Behrent (2016) lembra que "diferenças", "tolerância", "práticas minoritárias", são expressões comumente associadas ao ideário político foucaultiano. Audier (2015) relata que, antes de ministrar seus cursos sobre governamentalidade, Foucault ficou impactado, durante suas viagens à Califórnia, com a liberdade das práticas sexuais e de uso de drogas, além do vigor da comunidade homossexual em São Francisco. De fato, a sociedade (neo)liberal estadunidense foi protagonista da construção de políticas 
das minorias, ao mesmo tempo em que o governo liberal de Giscard D'Estaing também avançava em mudanças de legislação na mesma direção ${ }^{1}$. Foucault observou nessas práticas de tolerância (neo)liberais, um prenúncio da crise da ordem disciplinar e a emergência de outras modalidades de governo menos disciplinarizadoras, operando através das tecnologias de segurança, tema central em seus cursos de 1978 e 1979.

A entrevista dada em 1983 a Robert Bono, compôs uma coletânea sobre seguridade social, escrita por intelectuais ligados à Segunda Esquerda francesa. Intitulada "Um sistema finito diante de uma demanda infinita"2 (Foucault, 1983/2004b), discute sobre como lidar com a crise, desencadeada dez anos antes, ligada ao descompasso entre a demanda crescente pela seguridade social, diante dos limites desse sistema?

Em sua primeira intervenção, Foucault aponta os três elementos que circunscrevem sua análise: o sistema da seguridade criado em 1946, se choca hoje com os obstáculos econômicos conhecidos; seu modelo conceitual, conhece hoje seu esgotamento; o sistema tem efeitos perversos, pela rigidez de certos elementos e pela produção de dependências. Os três pontos não têm a mesma importância na entrevista. $\mathrm{Na}$ verdade, os dois primeiros formam certa moldura do debate. Mas o terceiro é o eixo central da problematização foucaultiana. É o mais explorado na entrevista e esboça o que seria um caminho desejável da seguridade social, tendo por pano de fundo a noção de autonomia. Essa alternativa será apresentada, de modo exploratório, no decorrer da entrevista. Dentro desse enquadre, os três pontos problemáticos da seguridade social, e uma alternativa experimental a ser implementada, será feita a análise dessa entrevista.

O primeiro ponto, os limites econômicos colocados ao sistema da seguridade, é um argumento de origem neoliberal. Foucault não problematiza o limite econômico colocado diante do sistema, mas explica, como, no campo da saúde, esse limite se manifesta. Segundo ele, haveria entre as capacidades técnicas da medicina e as capacidades econômicas de uma coletividade, uma linha móvel que tenderia ao desequilíbrio decorrente do permanente aumento da demanda. Afirma enfaticamente, "não vejo e ninguém pode me explicar como, tecnicamente, seria possível satisfazer todas as carências de saúde na linha interminável em que se desenvolvem" (Foucault, 1983/2004b, p. 138). Dessa condição foi extraída o título da conversa e outros aspectos dessa questão são explorados nos outros pontos.

No segundo ponto, Foucault explora a antiguidade do modelo social no qual se baseou o Estado-Providência.

1 Apesar da política de minorias ser hoje uma bandeira das esquerdas, sua gênese não se deu com elas. Eribon sugere que uma das razões pelas quais Foucault abandonou o PCF foi devido à sua condição homossexual, pois o partido "condenava o homossexualismo como um vício da burguesia" (1990, p. 69).

2 Tradução minha, acompanhando o original francês: "Um système fini face à une demande infinie" (Foucault, 1994, p. 367).
Aponta que foi concebido na primeira metade do século $\mathrm{XX}$, atribuindo seu ideário aos ingleses Beveridge e Keynes. Considera que foi um trabalho de grande importância, mas que não se atualizou com a mudança dos tempos, nada surgindo de novo ${ }^{3}$, o que ficou claro na crise que já durava 10 anos. Lembra que quando surgiu, a seguridade social buscava enfrentar o que podemos chamar de "carências da saúde". Ou seja, "os afastamentos por invalidez ligados à doença, assim como às deficiências congênitas ou adquiridas" (p. 136). Atualmente, com o desenvolvimento das tecnologias médicas e o crescimento da demanda por saúde, ampliou-se de modo ilimitado o que pode ser considerado como "carências de saúde".

Seu diagnóstico é "carecemos totalmente de instrumentos intelectuais para examinar em novos termos a forma pela qual poderíamos atingir o que buscamos (Foucault, 1983/2004b, p. 133). O entendimento de Foucault é que essa situação de crise não será equacionada apenas no manejo do limite econômico, como visto no item anterior, mas será necessário a construção de novos instrumentos intelectuais, ou, recorrendo à linguagem contemporânea, de novas tecnologias sociais.

O terceiro ponto analisa os efeitos perversos do sistema. $\mathrm{O}$ aspecto mais explorado é o efeito de dependência decorrente da oferta de segurança por parte do Estado. Foucault afirma que no pós-guerra a questão da segurança era, de fato, vital. Posteriormente, a partir dos anos 1960 o tema da independência emergiu na arena social. Dean (2016) sugere que esse é o diagnóstico neoliberal, que o Welfare State gera uma dependência, irresponsável e onerosa. Porém, a avaliação de Foucault (1983/2004b) vai além dessa simplificação neoliberal. Ele distingue a dependência por integração, que compõe o diagnóstico neoliberal, da dependência por exclusão, apontando o fracasso das políticas de universalização e enfatizando: "Contra ambos é preciso reagir" (p. 128). Foucault ainda aponta que a seguridade social submete os indivíduos e grupo a determinado "modo de vida" que quando não alcançado produz marginalizações (p. 131). Assim, se por um lado é inegável que Foucault acolhe aspectos da perspectiva neoliberal, por outro ele não se restringe a eles, mas traz outros elementos ao debate que são estranhos à lógica neoliberal, como o princípio da universalização. Essa acolhida a elementos do neoliberalismo pode explicar a razão de ter recebido a alcunha de neoliberal, entretanto, não a justifica. Apenas revela como Foucault não rezava uma cartilha política partidária, ou de esquerda, mas buscava em seus estudos, encontrar instrumentos para pensar diferentemente das diferentes tradições políticas. $\mathrm{O}$ que encontramos, neste texto e em outros, é a firme defesa

3 Os estudos atuais sobre seguridade social têm um diagnóstico, em parte, distinto de Foucault. De um lado não há de fato um novo modelo de Welfare State comparável a 1946, mas por outro há um conjunto de mudanças de caráter incremental, que têm reconfigurado gradualmente diversas experiências de seguridade social, com trocas e influências mútuas entre diversos países (Sandermann, 2014). 
do direito dos governados, de uma subjetivação que produz normatividade. Aliás, o sentido etimológico de autonomia é exatamente a capacidade de se autogovernar, de estabelecer suas próprias normas, o que um eixo central da crítica foucaultiana, possuindo inelutavelmente uma dimensão político-normativa.

Ao reconhecer a impossibilidade do crescimento das despesas no ritmo em que vem se dando, Foucault (1983/2004b) pergunta, quem vai decidir por isso, a autoridade estatal ou os usuários? Propõe então uma descentralização, "para aproximar os usuários dos centros de decisão dos quais eles dependem e os associar aos processos de decisão" (p. 132). Foucault enfatiza a importância do que chama distância decisória, "uma distância ideal entre uma decisão tomada e o indivíduo a quem ela se aplica" (p. 135). Entende que deve se saber "por qual arbitragem, sempre flexível, sempre provisória, serão definidos os limites desse acesso" (p. 137). Sua proposta é que o enfretamento desses problemas complexos não deve ser por um regulamento único, mas por uma "nuvem de decisões", que permitam variações, sustentadas por algum consenso ético, mediante o qual o usuário se reconheça nas decisões tomadas e nos valores que os inspiraram" (p. 141). Desse modo, o sujeito na linguagem da seguridade social, entendido como assujeitado, submetido a regras da burocracia, passaria a ocupar a condição de sujeito produtor de normatividade, que coloca em questão sua relação com o Estado. Infelizmente, segundo o filósofo, só nos colocamos a pergunta sobre a natureza de nossa relação com o Estado, face à perda ou restrição de benefícios, decisão, de fato, tomada por poucos.

Nesse ensejo de buscar aproximar dos usuários do sistema a arbitragem sobre suas escolhas, Foucault $(1983 / 2004 b)$ entende que precisaríamos reexaminar as racionalidades que as presidem, pois "tais escolhas estão sendo tomadas a cada instante, embora isso não seja dito" (p. 139). Ou seja, os governos fazem escolhas no campo da saúde pública, constantemente, mas nem sempre os usuários do sistema têm clareza que direção está sendo tomada. Assim, Foucault insiste no direito dos governados de participarem das decisões, ainda que a arquitetura desse processo necessite ser inventada.

Foucault (1983/2004b) estuda o passado não para reproduzi-lo, mas para poder pensar diferentemente nossa atualidade. As soluções das questões políticas atuais não estão nos ideários já existentes, marxismo ou neoliberalismo, o que não o impediu de buscar contribuições teóricas em ambos, ao mesmo tempo em que se recusava a assumir quaisquer dessas bandeiras como a priori. Dean (2015, p. 399) aponta que Foucault demonstrava boa vontade com a adoção de soluções tomadas de empréstimo do neoliberalismo, por parte da Segunda Esquerda francesa. Nessa mesma direção, Colin Gordon sugere que Foucault poderia ser lido como quem desafia os socialistas a observarem os avanços das democracias sociais, que realizaram uma incorporação seletiva de estratégias neoliberais (Donzelot \& Gordon, 2008, p. 52).

Esse hibridismo teórico-político representou um esforço feito pelo filósofo de escapar dos efeitos moralizantes que as classificações binárias geram. Buscava escapar inclusive de sua própria teorização de biopolítica, ainda centrada na noção de enfrentamento, e no par "poder-resistência", que induzia a ideia de que a nobreza política pertence à resistência e que o poder é o mal ${ }^{4}$. A noção de governo lhe permitiu avançar em análises mais complexas, reconhecendo que o campo da política é um estado misto, cinzento, não podendo ser capturado por classificações binárias e moralizantes (Ferreira Neto, 2015).

Tendo a concordar com a avaliação de seu amigo e colaborador Paul Veyne (2008), em seu livro sobre o pensamento e a obra de Foucault, que considera que apesar de ser tido com "esquerdista", ele nunca foi um homem de esquerda ou de direita, mesmo que estrategicamente houvesse buscado os esquerdistas como parceiros em suas lutas pontuais (p. 201). Faço apenas uma ponderação ao comentário de Veyne. No convívio com os maoístas e nos estudos sobre o neoliberalismo, Foucault não portava um semblante desinteressando, ao contrário, buscava neles, em uma atitude não preconceituosa, referências que lhe permitissem fazer avançar suas análises.

Outro aspecto a ser destacado quanto à posição de Foucault é sua defesa do "caráter local da crítica" (Foucault. 1976/1999, p. 10). Entende-se local com a análise de um acontecimento com um recorte histórico e geográfico preciso, evitando-se as generalizações. Portanto a noção de contraconduta, ou de subjetivação não é uma postura política de princípio, mas uma afirmação relacional. Buscase "transformar uma situação específica" (Lorenzini, 2016, p. 11), a nível localizado. Com base nesse caráter local da crítica pode-se aproximar o trabalho de Foucault daquele realizado pelos cientistas sociais, de estudos comparados de políticas públicas e o neoinstitucionalismo (Flew, 2012). Nesses estudos busca-se entender uma realidade localizada, dentro da institucionalidade que lhe é própria, sem uma referência normativa padronizada.

4 Segundo Castro-Gomez (2011), após o lançamento de História da sexualidade I, Foucault foi acusado de sustentar um "modelo rígido e dualista do poder", alicerçado nas categorias de poder e resistência. O próprio filósofo falava de seu "modelo binário da guerra, da luta, do enfrentamento das forças", como algo a ser reavaliado (Foucault, 1997/1999, p. 26). Porém, há que se ponderar que Foucault, retrospectivamente, tendeu a acentuar em demasia a diferença entre os dois modelos, mesmo que encontremos desde Vigiar e Punir, uma preocupação em descrever certa positividade do poder. O que se pode sugerir é que com o conceito de governamentalidade ele criou uma alternativa mais incisiva para se contrapor ao binarismo. 


\section{CONSIDERAÇÕES FINAIS}

Foucault não era um marxista, nem um neoliberal (Bang, 2015). Mesmo assim, bebeu em ambas as fontes, principalmente na primeira. Marx foi-lhe uma importante influência intelectual. Entre os anos 1976 e 1980, considerou ser necessário "se desembaraçar do marxismo", porém não achava "pertinente acabar com o próprio Marx" (Foucault, 1978/2010c, p. 191). Nos seus últimos anos, de um lado, aproximou-se da Segunda Esquerda, e por outro foi um crítico combativo do governo socialista de Mitterrand, eleito democraticamente em 1981. Ao analisar a crise da seguridade social na França, acolheu certos aspectos da crítica neoliberal, mas colocou no centro da discussão o problema da autonomia e da arbitragem, que inclui a participação dos usuários na definição dos possíveis limites ao acesso.

Concordo com as críticas de alguns foucaultianos ao uso generalizador da classificação de neoliberalismo, cumprindo uma função mais retórica que analítica. A experiência de boa parte dos países tende a operar com uma mistura de tendências no campo das políticas públicas, combinando receitas de origem neoliberal e socialdemocratas. Por isso temos processos muito similares ocorrendo em países de diferentes tradições políticas, como mostra Trianfillou (2012), em seu estudo comparativo sobre a Grã-Bretanha, Dinamarca e França. Interpretar isso como a dominação global do neoliberalismo, me parece excessivo e pouco explicativo. Numa perspectiva foucaultiana, precisamos realizar análises específicas de como essas combinações se dão, que jogos estratégicos ela favorece ou prejudica nas situações locais e nacionais. De qualquer modo, Foucault não reduzia a política ao enfrentamento entre dois projetos, mas considerava-a um campo complexo com estratégias plurais de micropoderes, que ele passou a explorar dentro da perspectiva da governamentalidade.

O mergulho de Foucault nos temas políticos clássicos, tais como o Estado e a economia política, mediante o olhar micropolítico da governamentalidade, o conduziu a um deslocamento derradeiro na direção da subjetivação e da ética. O desembaraçar-se do marxismo, não foi apenas um processo intelectual, mas um processo de subjetivação, que lhe acarretou custos e rupturas, pessoais e institucionais. Em decorrência disso, ele começou a teorizar sobre o direito mais historicamente determinado, o "direito dos governados", animado pela questão: "como se tornar sujeito sem ser sujeitado?".

A subjetividade coloca-se para Foucault na interface entre a política, como indicado acima, e a ética, entendida também como cuidado de si. O sujeito é efeito de práticas de sujeição e práticas de liberdade, produzidas no ambiente cultural no qual habita. Essa perspectiva, se por um lado, tensiona a tradição da Psicologia que a reduz à interioridade psicológica, por outro, abre possibilidades de tecermos conexões entre a experiência subjetiva e as condições sociais, culturais e institucionais singulares em que vivemos. O diálogo desenvolvido sobre esse tema com o filósofo, também graduado em Psicologia, Michel Foucault, pode se revelar profícuo para a área.

\section{REFERÊNCIAS}

Audier, S. (2015). Neoliberalism through Foucault's eyes. History and Theory, 54, 404-418.

Bang, H. P. (2015) Foucault's political challenge: From hegemony to truth. London, UK: Palgrave Macmillan.

Bastos, A. V. B., \& Gondim, S. M. G. (Org). (2010). O trabalho do psicólogo no Brasil. Porto Alegre: Artmed.

Behrent, M. (2010). Accidents happen: François Ewald, the "antirevolutionary" Foucault, and the intellectual politics of the French Welfare State. The Journal of Modern History, 82(3), 585-624.

Behrent, M. (2016). Liberalism without humanism: Michel Foucault and the free-market creed, 1976-1979. In D. Zamora \& M. Beherent (Orgs.), Foucault and Neoliberalism (pp. 24-62). Cambridge: Polity Press.

Castro-Gómez, S. (2011). Historia de la gubernamentalidad. Bogotá: Siglo del Hombre Editores.

Cotoi, C. (2011). Neoliberalism: A foucauldian perspective. International Review of Social Research, 1(2), 109-124.

Dardot, P., \& Laval, C. (2016), A nova razão do mundo: Ensaio sobre a sociedade neoliberal (M. Echalar, Trad.). São Paulo: Boitempo.

Dean, M. (2016). Foucault, Ewald and Neoliberalism. In D. Zamora \& M. Beherent (Orgs.), Foucault and Neoliberalism (pp. 85113). Cambridge: Polity Press.
Dean, M. (2015). Foucault must not be defend. History and Theory, 54, 389-403.

Defert, D. (1999). Cronologia. In Foucault. Problematização do Sujeito: Psicologia, psiquiatria e psicanálise (pp. 1-64). Rio de Janeiro: Forense Universitária.

Donzelot, J., \& Gordon, C. (2008). Governing liberal societies: The Foucault Effect in the English-speaking word. Foucault Studies, 5, 48-62.

Elden, S. (2016). Foucault's last decade. Cambridge: Polity Press. Eribon, D. (1990). Michel Foucault, 1926-1984. (H. Feist, Trad.). São Paulo: Companhia das Letras.

Ferreira Neto, J. L. (2015). Pesquisa e metodologia em Michel Foucault. Psicologia: Teoria e Pesquisa, 31, 411-420.

Ferreira Neto, J. L., Moreira, J. O., Araujo, J. N. G., \& Drawin, C. R. (2017). Usos de Foucault nos estudos de psicologia no Brasil. Psicologia e Sociedade, 29, e159930.

Flew, T. (2012). Michel Foucault's The birth of biopolitics and contemporary neoliberalism debates. Thesis Eleven, 108(1), 44-65.

Foucault, M. (1978). O que é a crítica? Crítica e Aufklärung (G. Borges, Trad.). Recuperado de http://portalgens.com.br/portal/ images/stories/pdf/critica.pdf.

Foucault, M. (1994). Um système fini face à une demande infinie. In Dits et Écrits IV 1980-1988 (pp. 367-382) Paris: Gallimard. 
Foucault, M. (1999). Em defesa da sociedade (M. Galvão, Trad.). São Paulo: Martins Fontes. (Original publicado em 1997)

Foucault, M. (2004a). É inútil revoltar-se? In Ética, sexualidade, política (E. Monteiro \& I. Barbosa, Trad., pp. 77-81). Rio de Janeiro: Forense Universitária. (Original publicado em 1978)

Foucault, M. (2004b). Um sistema finito diante de um questionamento infinito. In Ética, sexualidade, política (E. Monteiro \& I. Barbosa, Trad., pp. 126-143). Rio de Janeiro: Forense Universitária. (Original publicado em 1983)

Foucault, M. (2004c). Polêmica, política, problematizações. In Ética, sexualidade, política (E. Monteiro \& I. Barbosa, Trad., pp. 225-233). Rio de Janeiro: Forense Universitária. (Original publicado em 1984)

Foucault, M. (2004d). O cuidado com a verdade. In Ética sexualidade, política (E. Monteiro \& I. Barbosa, Trad., pp. 240-251). Rio de Janeiro: Forense Universitária. (Original publicado em 1983)

Foucault, M. (2004e). A ética do cuidado de si como prática da liberdade. In M. B. Motta (Org.), Ética, sexualidade, politica (E. Monteiro \& I. Barbosa, Trad., pp. 264-287). Rio de Janeiro: Forense Universitária. (Original publicado em 1984).

Foucault, M. (2008a). Segurança, território, população (E. Brandão, Trad.). São Paulo: Martins Fontes. (Original publicado em 2004)

Foucault, M. (2008b). Nascimento da biopolítica (E. Brandão, Trad.). São Paulo: Martins Fontes. (Original publicado em 2004)

Foucault, M. (2010a). Sobre a Justiça Popular. Debate com os maoístas. In Repensar a política (A. Pessoa, Trad., pp. 34-68). Rio de Janeiro: Forense Universitária. (Original publicado em 1972)

Foucault, M. (2010b). Michel Foucault: A segurança e o Estado. In Repensar a politica (A. Pessoa, Trad., pp. 170-175). Rio de Janeiro: Forense Universitária. (Original publicado em 1977)

Foucault, M. (2010c). Metodologia para o conhecimento do mundo: Como se desembaraçar-se do marxismo. In Repensar a politica (A. Pessoa, Trad., pp. 186-210). Rio de Janeiro: Forense Universitária. (Original publicado em 1977)
Foucault, M. (2012a). Uma mobilização cultural. In Segurança, penalidade e prisão (V. Ribeiro \& I. Barbosa, Trad., pp. 9192). Rio de Janeiro: Forense Universitária. (Original publicado em 1977)

Foucault, M. (2012b). Vão extraditar Klaus Croissant? In Segurança, penalidade e prisão (V. Ribeiro \& I. Barbosa, Trad., pp. 95-100). Rio de Janeiro: Forense Universitária. (Original publicado em 1977)

Foucault, M (2014a). O sujeito e o poder. In Filosofia, diagnóstico do presente e verdade (A. Chiaquieri, Trad., pp. 118-140). Rio de Janeiro: Forense Universitária. (Original publicado em 1982)

Foucault, M (2014b). Subjetividade e verdade. In Genealogia da ética, subjetividade e sexualidade (A. Chiaquieri, Trad., pp. 349-355). Rio de Janeiro: Forense Universitária. (Original publicado em 1981)

Karlsen, M., \& Villadsen, K. (2014). Foucault, Maoism, Genealogy: The influence of political militancy in Michel Foucault's Thought. New Political Science, 37(1), 91-117.

Kipnis, A. (2008). Audit cultures: Neoliberal governmentality, socialist legacy, or technologies of governing? American Ethnologist, 35(2), 275-289.

Lagasnerie, G. (2013). A última lição de Michel Foucault (A. Teles, trad.) São Paulo: Três Estrelas.

Lorenzini, D. (2016). From conter-conduct to critical atitude: Michel Foucault and the art of not being governed quite so much. Foucault Studies, 21, 7-21.

Sandermann, P. (Org.). (2014). The end of Welfare as we know it? Continuity and change in Western Welfare State, settings and practices. Berlin: Barabara Budrich.

Senellart, M. (2008). Situação dos cursos. In M. Foucault, Segurança, território, população (E. Brandão, Trad., pp. 495538). São Paulo: Martins Fontes.

Trianfillou, P. (2012). New forms of governing: A foucauldian inspired analysis. New York: Palgrave Macmillan.

Veyne, P. (2008). Foucault: As pensée, as personne. Paris: Albin Michel.

Zamora, D. (Org.). (2014). Critiquer Foucault: Les années 1980 et la tentation neoliberal. Bélgica: Les Éditions Aden. 